\title{
Análise dos Programas de Preparação para Aposentadoria (PPA) desenvolvidos por instituições públicas brasileiras
}

Analysis of Retirement Preparation Programs (RPA) developed by Brazilian public institutions

Análisis de los Programas de Preparación para la Jubilación (PPJ) desarrollados por instituciones públicas brasileñas

Lucia Helena de Freitas Pinho França Soniárlei Vieira Leite Fabrícia Prado Simões Thaysa Garcia Patrick Ataliba

RESUMO: Este estudo objetivou analisar as características dos Programas de Preparação para a Aposentadoria (PPA), desenvolvidos por 35 gestores ou coordenadores de PPA, em igual número de instituições públicas brasileiras. Por meio de questionário, os gestores avaliaram itens como tempo de existência, metodologia, temas abordados, processo de acompanhamento e avaliação dos programas. Metade dos programas tinha até dois anos de existência; a maioria utilizava palestras, dinâmicas, vivências, workshop e coaching. Em geral, raras organizações realizavam acompanhamento e avaliações sistemáticas, especialmente para comprovar a eficácia dos programas no bem-estar dos aposentados, após saída da organização. Recomendações são fornecidas visando à sistematização, expansão e avaliação do PPA no Brasil.

Palavras-chave: Programas de preparação para aposentadoria; Perfil; Conteúdos; Organizações. 
ABSTRACT: This study aimed to analyze the characteristics of the Retirement Preparation Programs (PPA), developed by 35 managers or coordinators in an equal number of Brazilian public institutions. Through a questionnaire, the managers evaluated items such as time of existence, methodology, topics covered in the programs and the process of monitoring and evaluation. Half of the programs were up to two years old, most used lectures, dynamics, experiences, workshops and coaching. In general, few organizations performed systematic monitoring and evaluation, especially to prove its effectiveness in the well-being of retirees after leaving the organization. Recommendations are provided for the systematization, expansion and evaluation of the PPA in Brazil.

Keywords: Retirement preparation programs; Profile; Contents; Organizations.

RESUMEN: Este estudio objetivó analizar las características de los Programas de Preparación para la Jubilación (PPJ), desarrollados por 35 gestores y por igual número de instituciones públicas brasileñas. En el cuestionario, los gestores evaluaron ítems como tiempo de existencia, metodología, temas abordados, proceso de seguimiento y evaluación de los programas. La mitad de los programas tenía hasta dos años de existencia, la mayoría utilizaba charlas, dinámicas, vivencias, taller y coaching. En general, raras organizaciones realizaban seguimiento y evaluación sistemáticas, especialmente para comprobar la eficacia de los programas en el bienestar de los jubilados, después de la salida de la organización. Las recomendaciones se suministran para la sistematización, expansión y evaluación del PPA en Brasil.

Palabras clave: Programas de preparación para la jubilación; Perfil; Contenido; Organizaciones.

\section{Introdução}

As últimas previsões do IBGE (2018) destacam que há cerca de 27 milhões de brasileiros com mais de 60 anos e que, em apenas duas décadas, serão 51 milhões - um acréscimo de aproximadamente $90 \%$. Dessa forma, a população brasileira acompanha o movimento global do processo de envelhecimento, embora em ritmo bastante acelerado. 
Este é um fenômeno complexo e multidimensional e, portanto, fundamental para reflexão na vida moderna, uma vez que o avanço científico e tecnológico impulsiona o aumento da expectativa de vida em proporções cada vez maiores.

Dentre os determinantes do rápido envelhecimento, destaca-se que, a partir de 1980, houve uma expressiva redução na taxa de fertilidade da população brasileira em conjunto com o aumento da esperança de vida ao nascer de vida. Nos primeiros 15 anos deste milênio, a esperança de vida subiu de 69,83 anos para 75,44 anos, ao mesmo tempo em que a taxa de fecundidade caiu de 2,4 para 1,72 (IBGE, 2013). Fatos que podem ser observados por meio da dinâmica populacionais e suas projeções, estreitamento da base de nascimento e alargamento do topo (IBGE, 2017).

Essas mudanças demográficas associadas às atuais leis previdenciárias nos levan a aferir que o brasileiro viverá aproximadamente 30 anos no gozo da aposentadoria (IBGE, 2017). Por este motivo, pesquisas que se dedicam a estudar o planejamento para esta fase da vida mostram-se relevantes para a qualidade daqueles que envelhecem.

No contexto organizacional, o fortalecimento dos trabalhadores mais velhos pode representar uma estratégia de planejamento e desenvolvimento (França, et al., 2014). Com o aumento do número de trabalhadores mais velhos e a diminuição dos mais jovens, será cada vez mais necessário identificar aqueles que desejam continuar trabalhando, valorizando seu conhecimento e experiência (Antunes, Soares, \& Silva, 2015).

Dessa forma, as práticas de gestão de conhecimento, a recolocação, a reorientação profissional e a continuidade no trabalho após a aposentadoria deverão fazer parte das atividades dos recursos humanos (Antunes, Soares, \& Silva, 2015; França, et al., 2014).

Um dos temas que tem recebido grande atenção é o planejamento para a aposentadoria. Nesse sentido, as questões previdenciárias, atuariais e financeiras, além dos aspectos psicossociais, de educação e de gestão, precisam ser abordadas.

Por se tratar de uma estratégia essencial ao bem-estar na aposentadoria, o planejamento deve ser estimulado desde o ingresso dos jovens no mercado de trabalho, podendo ser realizado individualmente ou por meio de ações e programas desenvolvidos pelas organizações (Earl, Gerrans, \& Halim, 2015; França, 1992; Leandro-França, Murta, Hershey, \& Martins, 2016; Sartori, Fraga, Vieira \& Coronel, 2016). 
A Organização das Nações Unidas (ONU, 1982), assumindo a urgência em tratar dos problemas do contingente populacional de idosos, apresentou o Plano de Ação Internacional de Viena sobre o Envelhecimento. O documento contém recomendações sobre a necessidade de uma transição gradual da vida do trabalho para a aposentadoria. No Brasil, a Política Nacional do Idoso - Lei n. 8.842 (Brasil, 1994) e o Estatuto Idoso - Lei n. ${ }^{\circ} 10.741$ (Brasil, 2003) regulam os direitos assegurados às pessoas com 60 anos ou mais. A legislação brasileira contempla a implantação e o desenvolvimento de Programas de Preparação para a Aposentadoria (PPA) pelas organizações. Cabe ressaltar que o Estatuto do Idoso recomenda que o PPA deva ser disponibilizado com antecedência mínima de um ano para os empregados que desejam se aposentar.

A prática do PPA foi iniciada no Brasil no final de 1980 (França, 1992) como uma resposta às diversas demissões de trabalhadores mais velhos, tendo em vista o processo de fusão das organizações. O objetivo do PPA é oferecer ao trabalhador as informações necessárias e fundamentais sobre a aposentadoria, identificando opções de atividades após a saída do mercado de trabalho e compartilhando experiências com outras pessoas que vivenciam um momento equivalente (Zanelli, 2012). O programa contribui, portanto, para que os "aposentandos" possam responder com menor sofrimento e mais otimismo às questões inerentes a esse momento e, consequentemente, viver mais e melhor (Murta, et al., 2014).

França (2016) ressalta que o objetivo do PPA também é contribuir para que o participante desenvolva habilidades e descubra novos interesses, sendo capaz de refletir sobre um projeto de vida e os investimentos necessários para alcançá-lo. A autora ressalta que existem diversas possibilidades de se implementar um PPA em uma organização, dependendo prioritariamente dos objetivos, políticas e normas organizacionais.

O PPA é uma ferramenta para essa transição, na medida em que oferece ao indivíduo possibilidades de ressignificar a própria vida, sob a perspectiva do trabalho. O planejamento para a aposentadoria pode ser representado por uma balança de ganhos e perdas (França, \& Vaughan, 2008), e a intervenção do PPA pode tornar as atitudes dos trabalhadores mais positivas em relação à decisão da transição trabalho/aposentadoria e compensar as perdas que possivelmente tenham nessa fase. Entre as dimensões dos ganhos apontadas pelos autores estão: a liberdade do trabalho, ter mais tempo para relacionamentos e lazer. No âmbito das perdas, estão: os relacionamentos referentes e os aspectos emocionais do trabalho, bem como os recursos financeiros e os benefícios. 
Em investigação sob a perspectiva de bem-estar na aposentadoria com servidores públicos de uma universidade, pesquisadores evidenciaram a falta de preparo dos préaposentados com relação a fatores de risco e sobrevivência para essa nova fase da vida (Bressan, Mafra, França, Melo, \& Loretto, 2013). Os autores apontaram para a importância de se ampliar estudos para avaliar interesses, semelhanças e diferenças que possam aparecer no perfil de cada amostra. Portanto, o PPA deve ser teoricamente embasado, implantado de acordo com as necessidades dos participantes e criteriosamente avaliado (Leandro-França, Murta, Hershey, \& Martins, 2016; Murta, et al., 2014).

Em outro estudo com trabalhadores de uma universidade, pesquisadores chegaram a conclusões similares ao analisarem as relações entre fatores sociodemográficos e ocupacionais e as percepções de ganhos e perdas na aposentadoria (Pissinati, Haddad, Dalmas $\&$ Birolim, 2016). Os autores destacam que conhecer o perfil dos trabalhadores é fundamental para compreender suas atitudes frente à aposentadoria. Os resultados encontrados também confirmam a necessidade da continuidade do programa, como forma de intervenção que ajude a reconhecer as vantagens e gerenciar as desvantagens existentes na aposentadoria.

Figueira, Haddad e Gvozd (2016) também apontaram a relevância do PPA por meio de uma pesquisa realizada em uma universidade pública, cujos resultados revelaram maiores chances de sucesso e satisfação na aposentadoria. Os autores constataram que a aposentadoria poderia ser percebida tanto como uma oportunidade a ser aproveitada - com a família e os amigos e em momentos de lazer ou de autocuidado - quanto como causadora de medos e incertezas.

Leandro-França, Seidl e Murta (2015) relatam a experiência de um PPA a partir de uma intervenção breve, na qual foram analisadas a evolução dos participantes nos estágios de mudança contemplados pelo modelo transteórico de mudança (Prochaska \& DiClemente, 1982), quais seja: pré-contemplação, a contemplação, a preparação, a ação e a manutenção. Os resultados indicaram que as mudanças mais relevantes estavam relacionadas ao maior engajamento em comportamentos de cuidado em saúde, relacionamento social e finanças.

Em outro estudo, Leandro-França, et al. (2016) analisaram os efeitos de três tipos de Programa de Preparação para Aposentadoria, na mudança dos participantes em se planejar para aposentadoria, a saber: intervenção continuada, intervenção breve e intervenção de testemunho.

\footnotetext{
França, L. H. de F. P., Leite, S. V., Simões, F. P., Garcia, T., \& Ataliba, P. (2019). Análise dos Programas de Preparação para Aposentadoria (PPA) desenvolvidos por instituições públicas brasileiras. Revista Kairós-Gerontologia, 22(1), 59-80. ISSNe 2176-901X. São Paulo (SP), Brasil: FACHS/NEPE/PEPGG/PUC-SP
} 
Para isso, os autores utilizaram o Modelo Transitório de Mudança (Prochaska, \& DiClemente, 1982), que compreende os diferentes estágios de mudança como ciclo, que se inicia com o cognitivo, passando para o motivacional, até chegar ao comportamental. Destaca-se que a intervenção continuada foi o único tipo de PPA, que proporcionou mudanças comportamentais efetivas, enquanto a intervenção breve e a de testemunho se limitaram às mudanças cognitivas e motivacionais.

Os programas possuem, entre suas estratégias, o planejamento futuro, no qual o trabalhador mais velho poderá encontrar suas potencialidades, identificando suas limitações e se preparando para possíveis conflitos que possam surgir no futuro. Levando em consideração os resultados positivos de estudos envolvendo PPA, é importante a continuidade de pesquisas que possam compreender o cenário brasileiro deste tipo de programa. Apesar da escassez de estudos publicados sobre o assunto, algumas instituições têm se destacado no desenvolvimento dessas ações, especialmente organizações do setor público, como Petrobras, Furnas, Serpro e governos federal, estaduais e municipais. Pode-se citar como exemplo o estado da Bahia com o programa "Prepare-se". Pontua-se que as universidades públicas têm um papel relevante no pioneirismo e continuidade dessas ações, destacando-se o PPA da Universidade Federal de Santa Catarina - UFSC (Zanelli, \& Silva, 1996), posteriormente intitulado "Aposentação" (Soares, Costa, Rosa, \& Oliveira, 2007) e a Universidade de Brasília, com o programa "Viva Mais!" (Leandro-França, Murta, \& Villa, 2014; Murta, et al., 2014).

Quanto à periodicidade, os programas podem variar em mensal, trimestral, semestral ou anual. Durante os encontros do PPA, podem ocorrer workshops, seminários e palestras, que levem à reflexão e discussão de determinados temas, conduzidos por profissionais tanto da organização quanto exteriores. Os conteúdos variam desde aspectos de planejamento financeiro, saúde, envelhecimento, e até vivências que contribuam para a elaboração do projeto de vida (França, 2016). Os projetos de vida pós-aposentadoria são estimulados e sistematizados para que o indivíduo possa, mais facilmente, colocá-los em prática de modo harmônico e eficaz. Entende-se que não apenas empresas e equipes de trabalho, mas os próprios indivíduos devem traçar objetivos, metas e estratégias - pessoais e profissionais quando em face da aposentadoria (Dingemons, Henkens \& Solinge, 2015). 
Partindo do pressuposto de que o PPA contribui para o planejamento e a decisão para a aposentadoria e se constitui em uma ação estruturante para o bem-estar nesta fase (França, Menezes, \& Siqueira-Brito, 2012), o conhecimento de como as organizações brasileiras desenvolvem tais programas poderá contribuir para a sua expansão e aperfeiçoamento, bem como o estabelecimento de políticas e práticas inovadoras na área. Desse modo, o objetivo deste estudo foi analisar o perfil do PPA aplicado em instituições públicas brasileiras.

\section{Método}

O presente estudo é uma survey realizada por conveniência com instituições públicas brasileiras que desenvolviam programas de preparação para aposentadoria - PPA, entre 2014 e 2016. Para fins da presente pesquisa, as instituições públicas foram consideradas como aquelas de capital público, sociedades de economia mista, empresas públicas e órgãos dos Poderes Executivo, Judiciário e Legislativo.

\section{Participantes}

Fizeram parte desta pesquisa 35 gestores ou coordenadores do PPA, que representavam suas organizações que se localizavam nas cinco regiões do país.

\section{Instrumento}

Foi utilizado questionário digital, com 16 questões abertas e fechadas. As questões abordavam características do programa, como: tempo de existência, duração, frequência dos eventos, conteúdo, método, formas de acompanhamento e avaliação.

\section{Procedimentos}

O banco de dados foi elaborado por diversos contatos de conhecidos que trabalhavam ou conheciam pessoas, e-mails e telefones de profissionais de grandes e médias organizações, selecionadas de diversas federações de comércio e indústria e bancos de dados participantes do III e IV Congresso Brasileiro de Orientação para a Aposentadoria (CONBOA), e

\footnotetext{
França, L. H. de F. P., Leite, S. V., Simões, F. P., Garcia, T., \& Ataliba, P. (2019). Análise dos Programas de Preparação para Aposentadoria (PPA) desenvolvidos por instituições públicas brasileiras. Revista Kairós-Gerontologia, 22(1), 59-80. ISSNe 2176-901X. São Paulo (SP), Brasil: FACHS/NEPE/PEPGG/PUC-SP
} 
participantes de pesquisas prévias sobre o tema. Após selecionar os e-mails atualizados, foram convidados 413 gestores de igual número de organizações para responder um questionário, obtendo-se a taxa de retorno de aproximadamente 11\%. Assim, foram obtidos 44 participantes. Destes, uma ínfima parcela era formada pelo setor privado, que foi desconsiderada para que fosse focada a maioria das organizações que era do setor público. Assim, a amostra dessa pesquisa foi finalmente constituída por 35 gestores.

O presente projeto de pesquisa foi submetido ao Comitê Ético de Pesquisa (CEP) da Universidade Salgado de Oliveira - UNIVERSO, através da Plataforma Brasil e foi aprovado sob o número CAAE 49471815.4.0000.5289.

\section{Análise dos Dados}

Após coleta, limpeza e categorização do banco de dados, a análise estatística descritiva foi realizada, utilizando-se o Statistical Package for the Social Science (SPSS) versão 22. Os resultados foram descritos, tendo por base seu agrupamento em três categorias: organização, metodologia utilizada, acompanhamento e avaliação dos programas.

\section{Resultados}

\section{Organização do PPA}

Tempo de existência

A pesquisa diagnosticou que, em $20 \%$ das organizações, os PPA eram desenvolvidos há menos um ano, o que demonstra um aumento da iniciativa de ações por parte das organizações quanto à preparação para a aposentadoria. Pouco mais da metade dos programas (57\%) é desenvolvido por período entre 2 e 4 anos.

Poucas organizações $(8,6 \%)$ desenvolvem pioneiramente este tipo de programa (20 anos ou mais), entre elas, a Petrobras e a Empresa Companhia Riograndense de Abastecimento. 
Periodicidade e frequência de eventos

A maior parte dos programas era desenvolvido de forma sistemática. No entanto, sua frequência mostrou-se variável. Grande parte realizava encontros mensais ao longo de um ano, ao passo que quase um quarto dos programas contava com encontros anuais - o que facilita a implementação pela gestão, bem como a consistência dos conteúdos abordados, permitindo maior engajamento e reflexão por parte dos participantes.

\section{Carga horária}

O estudo revelou que a maioria das organizações $(60 \%)$ realizava programas com carga horária de 25 horas ou superior. Quase um quarto delas (23\%) apresentou carga horária baixa ou muito baixa (até $8 \mathrm{~h}$ totais), e aproximadamente $17 \%$ delas tinha carga horária intermediária (de 9 a 24h totais). Entre todos, é oportuno considerar que quase $29 \%$ dos programas são realizados com carga horária superior a 36 horas e que, porventura, demonstram ser os programas mais consistentes.

\section{Metodologia aplicada}

Verificou-se que palestra é o método mais utilizado pelos programas $(91,43 \%)$, seguindo-se as dinâmicas (80\%), vivências (68\%), workshops $(17,14 \%)$ e coaching $(5,71 \%)$. Destaca-se que uma das empresas adota a modalidade "curso a distância".

\section{Critérios de participação}

Os dados revelam que, em 62,86\% das instituições, o critério de inclusão no programa é estar há mais de três anos de cumprir os requisitos legais para aposentadoria (tempo de contribuição e idade).

\section{Conteúdos abordados}

Constatou-se que os conteúdos mais frequentemente abordados eram: aspectos legais da aposentadoria/legislação (63,4\%), planejamento financeiro/finanças (53,7\%), saúde e projeto de vida (48,8\% cada), envelhecimento $(31,7 \%)$ e lazer, identidade, qualidade de vida e

\footnotetext{
França, L. H. de F. P., Leite, S. V., Simões, F. P., Garcia, T., \& Ataliba, P. (2019). Análise dos Programas de Preparação para Aposentadoria (PPA) desenvolvidos por instituições públicas brasileiras. Revista Kairós-Gerontologia, 22(1), 59-80. ISSNe 2176-901X. São Paulo (SP), Brasil: FACHS/NEPE/PEPGG/PUC-SP
} 
família (19,5\% cada). Pontua-se que outros temas também foram citados, porém em proporção menor: relacionamentos afetivos/sexuais $(17,1 \%)$, relacionamentos sociais e voluntariado (12,2\% cada), gerenciamento do tempo e espiritualidade (9,8\% cada) e educação $(7,3 \%)$.

\section{Acompanhamento e avaliação dos PPA}

\section{Acompanhamento}

Em quase a metade dos PPA (48,8\%), o acompanhamento do trabalhador restringe-se ao tempo do programa. Em proporção menor (34\%), o acompanhamento se estende ao período após o programa, porém, enquanto o trabalhador ainda mantém vínculo ativo com a organização.

Avaliação

Cerca de $91,43 \%$ dos programas eram avaliados. Contudo, em $75 \%$ dos casos, pelo próprio coordenador do programa. Em 18,19\% pelos participantes já aposentados e 6,81\% por um técnico ou gestor diverso do coordenador.

\section{Discussão}

A partir dos resultados apresentados pela pesquisa, como pode ser observado na tabela 1 abaixo, foi possível delinear um perfil dos PPA, quanto ao tempo, de existência, periodicidade e carga horária, desenvolvidos pelas empresas públicas no Brasil, tendo por base os indicadores da literatura sobre o tema. Sendo a aposentadoria um tema complexo, que vai muito além do desligamento das atividades laborais e recebimento de proventos sob nova rubrica legal, sua abordagem deve ser multidimensional e abarcar uma série de questões de potencial impacto na vida do indivíduo, na ausência do trabalho. 
Os principais eixos temáticos do PPA contemplam a legislação, família, lazer, finanças, amigos, espiritualidade, saúde e até mesmo trabalho, voluntário ou remunerado (França, 2002). Essa visão foi corroborada por Leung e Earl (2012) e Kerry (2018), quando argumentam que, para o alcance de uma aposentadoria satisfatória e com qualidade de vida, o indivíduo precisa ter uma variedade de recursos, tais como: físicos, financeiros, sociais e psicológicos.

\section{Tabela 1}

Perfil dos Programas de Preparação para Aposentadoria desenvolvidos nas organizações públicas brasileiras

\begin{tabular}{|c|c|c|}
\hline Itens & Respostas & Frequência $(\%)$ \\
\hline \multirow[t]{4}{*}{ Tempo de existência } & Até um ano & 27,3 \\
\hline & De um a dois anos & 12,7 \\
\hline & De dois a seis anos & 25 \\
\hline & Mais de seis anos & 25 \\
\hline \multirow[t]{2}{*}{ Periodicidade } & Sistemático & 86,4 \\
\hline & Assistemático & 13,6 \\
\hline \multirow[t]{6}{*}{ Carga horária (horas) } & Menos de 4 horas & 14,28 \\
\hline & De 4 a 8 horas & 8,57 \\
\hline & De 09 a 12 horas & 0 \\
\hline & De 13 a 24 horas & 17,15 \\
\hline & De 25 a 36 horas & 31,43 \\
\hline & Mais de 36 horas & 28,57 \\
\hline \multirow[t]{3}{*}{ Frequência dos eventos } & Mensal & 40,9 \\
\hline & Trimestral a semestral & 34,1 \\
\hline & Anual & 25,0 \\
\hline \multirow[t]{2}{*}{ Tempo para a aposentadoria dos participantes } & Até dois anos antes & 56,8 \\
\hline & Mais de dois anos antes & 43,2 \\
\hline \multirow[t]{2}{*}{ Realização de avaliação } & Realizam & 86,4 \\
\hline & Não realizam & 13,6 \\
\hline \multirow[t]{4}{*}{ Responsável pela avaliação } & O próprio coordenador & 65,0 \\
\hline & Os participantes do programa & 20,0 \\
\hline & Um técnico/gestor & 10,0 \\
\hline & Consultor externo & 5,0 \\
\hline \multirow[t]{5}{*}{ Métodos utilizados } & Palestras & 97,7 \\
\hline & Dinâmicas & 77,3 \\
\hline & Vivências & 70,5 \\
\hline & Workshops & 34,1 \\
\hline & Coaching & 23,3 \\
\hline \multirow[t]{3}{*}{ Acompanhamento } & Durante o programa & 48,8 \\
\hline & Após o programa (ainda trabalhando) & 34 \\
\hline & $\mathrm{Na}$ aposentadoria & 18,2 \\
\hline
\end{tabular}


O foco deste trabalho foram as instituições públicas brasileiras. França (2016) aponta que $90 \%$ das organizações que solicitam consultoria sobre os PPA são oriundas do setor público. Tal constatação pode ser respaldada pela legislação brasileira que recomenda fortemente a implantação de PPA: Lei n. ${ }^{\circ} 8842$ (Brasil, 1994) e Lei n. ${ }^{\circ} 10.741$ (Brasil, 2003). Embora não exista fiscalização, o setor público tende a cumprir mais fortemente as recomendações dessa legislação, em função do compromisso com as diretrizes e normativas próprias do setor público e de sua responsabilidade social.

\section{Conteúdo}

Os conteúdos mais abordados pelas organizações analisadas estão relacionados à previdência social, finanças, projeto de vida e saúde, seguidas por envelhecimento, lazer e relacionamentos familiares.

Em menor proporção, os relacionamentos sociais, qualidade de vida, identidade, relações afetivo/sexuais, autoestima/imagem, voluntariado, gerenciamento do tempo/interesses, espiritualidade e educação.

Tais dados se ajustam com o que é apontado na literatura: temas relacionados às decisões vinculadas à aposentadoria (Figueira, Haddad, Gvozd, \& Pissinati, 2017; França, 2002, 2016; Zanelli, 2012; Zanelli, Silva, \& Soares, 2010), em que os programas priorizaram os assuntos relacionados à sobrevivência em detrimento dos outros assuntos também abordados.

A literatura aponta para uma série de conteúdos que, por terem impacto na aposentadoria, são considerados fundamentais em programas, ações e discussões sobre o tema. Entre eles, destacam-se recursos físicos, cognitivos, motivacionais, financeiros, sociais e emocionais que podem antecipar os fatores de risco ligados ao bem-estar dos aposentados (Leung, \& Earl, 2012; Wang, \& Shi, 2014).

Contemplam também a rede de apoio social (Wang, \& Shultz, 2010), relacionamentos e atividades diversificadas (França, 2016), além da qualidade de vida individual e coletiva (Peiró, Tordera, \& Portocnik, 2012), envelhecimento e saúde (Leandro-França, Murta, Hershey, \& Martins, 2016). 


\section{Sistematização, frequência e regularidade}

Foi observada certa regularidade no PPA entre seu desenvolvimento e sua carga horária de 25 horas ou mais, em mais da metade dos programas. Apesar de a literatura recomendar a preparação no maior período de tempo possível (Earl, Gerrans, \& Halim, 2015; França, 2016), o modelo de intervenção breve vem sendo demonstrado como alternativa viável para mudanças de comportamento (Leandro-França, Murta, \& Villa, 2014). Esta forma de adesão tem sido observada nos programas com menos de 24 horas de duração (43\%).

Constatou-se que a maioria das organizações permitia que trabalhadores, com até dois anos antes de se aposentar, participassem do programa, o que é bem-visto por pesquisadores da área (Bressan, Mafra, França, Melo, \& Loretto, 2013; Leandro-França, Murta, Hershey \& Martins, 2016; Murta, et al., 2014), além de recomendado por políticas públicas, conforme as leis já citadas. França e Soares (2009) ressaltam que um bom planejamento para a aposentadoria deve se antecipar e não ser muito próximo à interrupção das atividades laborais, ou seja, realizado a tempo de contribuir, seja na decisão de continuar trabalhando, retornar ao trabalho de outra maneira ou interromper definitivamente suas atividades. A preparação eficaz conduz à satisfação e ao ajustamento pós-aposentadoria (Wang, Henkens, \& Solinge, 2011).

\section{Métodos de trabalho}

Zanelli (2012) e França $(2012,2016)$ ressaltam que atividades em grupo, visando à interação entre pessoas, proporcionam discussão e reflexão sobre o sentido da vida, auxiliam no enfrentamento de momentos difíceis, ressignificando situações estressantes, e principalmente reforçando aspectos positivos de se ter mais tempo para priorizar o bem-estar. Em relação aos métodos de trabalho, todas as empresas participantes utilizavam palestras como forma de abordagem, bem como vivências e dinâmicas. Apesar da facilidade em realizar palestras sobre os temas escolhidos, França e Soares (2009) apontam que o método deve se adequar ao público-alvo e ao tempo disponível, podendo ser adaptado às possibilidades da organização.

Ainda sobre a adequação dos métodos aos diferentes objetivos dos programas, França (2002) avaliou a importância de palestras para conteúdos que abordem questões da qualidade de vida de todos, independentemente da proximidade da aposentadoria, como uma primeira etapa.

\footnotetext{
França, L. H. de F. P., Leite, S. V., Simões, F. P., Garcia, T., \& Ataliba, P. (2019). Análise dos Programas de Preparação para Aposentadoria (PPA) desenvolvidos por instituições públicas brasileiras. Revista Kairós-Gerontologia, 22(1), 59-80. ISSNe 2176-901X. São Paulo (SP), Brasil: FACHS/NEPE/PEPGG/PUC-SP
} 
A autora ressalta que em um segundo momento, voltado para aqueles que já sabem quando irão se aposentar, os aspectos vivenciais devem ser priorizados, por trazerem reflexões sobre situações imediatamente relacionadas aos futuros aposentados, considerando os seus interesses, possibilidades e projetos de vida (França, 2002).

\section{Avaliação e acompanhamento}

A avaliação e o acompanhamento dos participantes durante e após a realização do PPA e também na aposentadoria, demonstrou a necessidade de maior atenção. A maioria dos gestores apontou haver avaliação, porém em grande parte realizada pelo próprio coordenador. Além disso, a maior parte dos programas realizava acompanhamento dos participantes somente durante sua participação no mesmo.

Pontua-se que, quanto mais diversas forem as fontes de avaliação, mais neutra e construtiva ela se torna. Avaliações realizadas apenas por gestores e coordenadores podem gerar vícios de percepção e desconsideração de pontos de vista diversos, relevantes para o aprimoramento dos programas (França, 2016).

Considerando-se a necessidade do caráter continuado do processo de planejamento para a aposentadoria, o acompanhamento é primordial para avaliar em que medida os participantes se mantiveram informados e capazes de superar situações adversas, mantendo contato com os mesmos por mais tempo (Bressan, Mafra, França, Melo, \& Loretto, 2013; Leandro-França, Murta, Hershey, \& Martins, 2016); sendo que a avaliação deve ocorrer em diferentes momentos e diversos níveis de informação (Zanelli, Silva, \& Soares, 2010).

França $(2002,2016)$ ressalta a importância da avaliação e acompanhamento que sejam realizados de forma sistematizada, possibilitando a comprovação dos resultados, divul gação e aprimoramento do PPA.

A avaliação após a aposentadoria deve continuar a ser realizada por pelo menos cinco anos, de modo que se possa tanto avaliar o impacto do PPA e permitir ajustes de melhoria contínua, quanto realizar intervenções pontuais que venham a contribuir com o processo de adaptação à aposentadoria do participante (França, 2016). Contudo, este estudo destacou que apenas $18 \%$ realizavam acompanhamento após a aposentadoria, devendo ser investigados os motivos que levam à não adoção desta prática e à não comprovação da eficácia do PPA. 
Limitações e sugestões para futuras pesquisas

Esta pesquisa possui algumas limitações: a) a limitação numérica da amostra, o recorte específico (somente organizações públicas); b) a utilização de instrumento simples (em futuros estudos; c) a necessidade de identificar a clareza dos objetivos do PPA, a intenção política da organização e o diagnóstico institucional; d) identificar a qualificação da equipe envolvida no PPA; e) visita às organizações que atuam com o PPA de forma a acompanhar a sua prática e a tipificação de modelos de PPA; f) avaliar a percepção dos gestores sobre os benefícios que eles veem nos participantes que frequentaram o PPA.

Sobre a limitação numérica da amostra, pode-se afirmar que não tornou possível análises estatísticas mais robustas e generalizações. Não é possível garantir, ainda, os motivos pelos quais as organizações não responderam aos questionários. Dentre as poucas que deram alguma explicação, os motivos apresentados estava o não desenvolvimento do programa, por não estarem com tempo para preencher o questionário, ou não estarem autorizadas a responder pela organização. Assim, apesar dos critérios metodológicos e inúmeros contatos para obter a participação de 35 organizações públicas que desenvolviam o programa, não é possível considerar a amostra como representativa de PPA do setor público brasileiro.

Entre as sugestões para pesquisas futuras sobre o PPA, está a realização de estudos sobre a decisão da aposentadoria em diferentes contextos organizacionais e a discussão das suas possibilidades, incluindo a continuidade no mercado do trabalho, favorecida ou não pela redução de carga horária e a oferta de tarefas mais flexíveis, como o bridge employment (Menezes, \& França, 2012) ou blended work (Damman, 2016). Guerson, França e Amorim (2018) identificaram que o sentimento de produtividade e de realização pessoal estão correlacionados à satisfação com a vida de aposentados que continuaram a trabalhar. Esses resultados apontam que o retorno ao mundo do trabalho pode ser uma opção.

No que diz respeito à academia e às organizações, está a necessidade das parcerias na realização de pesquisas interinstitucionais e a oferta de instrumentos de mensuração para as ações de acompanhamento e da avaliação dos PPA. A convivência dos aposentáveis com os aposentados da mesma organização deve ser estimulada, assim a Associação de Aposentados deve estar vinculadas ao PPA, pela continuidade da participação do colaborador na organização e a realização de projetos sociais e de lazer comuns. Os Programas de Gestão de Conhecimento, apesar de raros, também deveriam estar associados ao PPA, visto que ambos reforçam o valor e a memória dos trabalhadores na história das organizações. 
Do ponto de vista das organizações, é fundamental que os departamentos/setores de Gestão de Pessoas promovam reflexões, de modo a repensar medidas de produtividade e qualidade, introduzindo estratégias durante ou pós-carreira, de forma a valorizar o conhecimento e experiência que podem ser utilizados dentro e fora das organizações. Outras ações de pesquisas precisam ser realizadas no que diz respeito aos preconceitos quanto ao envelhecimento no contexto organizacional, programas de educação ao longo da vida e medidas ergonômicas que permitam a continuidade da participação dos trabalhadores mais velhos no mercado do trabalho.

\section{Considerações Finais}

A pesquisa revelou que poucas organizações adotam o PPA, embora eles tenham sido iniciados há cerca de 30 anos, e contarem com o reforço da legislação. Muitas organizações ainda não estão preparadas para desenvolvê-lo e outras parecem carecer de vontade política ou serem despertadas por um gestor que advogue a seu favor.

A maior adesão das organizações ao PPA poderia ser a oferta, não para o planejamento para a aposentadoria, mas para o planejamento ao longo da vida, focado na promoção do projeto de vida dos trabalhadores brasileiros, que culturalmente não foram estimulados a pensar no futuro. O PPA é uma forma eficaz de apoio ao trabalhador mais velho na decisão, transição e adaptação frente aos riscos e o bem-estar na aposentadoria.

Apesar das dificuldades e limitações encontradas na coleta de dados, algo ainda difícil de ser realizado pela academia com organizações no Brasil, o presente estudo oferece um panorama dos PPA realizados no Brasil e representa uma avaliação dos mesmos, com apontamentos importantes para futuras investigações que adotem novas estratégias de acesso às organizações no âmbito individual, grupal e organizacional. Foram constatados pontos positivos nos programas incluídos nesta pesquisa, como a sua realização sistemática, a presença de sistema de avaliação do programa, o acompanhamento dos participantes enquanto realizavam o PPA e a quase universalização dos temas abordados. Há uma tendência de sistematização e continuidade do PPA dentro das organizações, fato observado pelo tempo que os programas existem, mesmo sabendo que, em crises financeiras, os programas voltados para os recursos humanos são mais suscetíveis ao desaparecimento. 
Apesar da reconhecida importância atribuída ao PPA, ao acompanhamento e à avaliação dos participantes, ele ainda depende de ajustes por parte das organizações. O acompanhamento dos participantes é um fator determinante para a avaliação e o redimensionamento do programa, já que o alcance de seus objetivos está relacionado ao ajuste e bem-estar deste trabalhador após seu desligamento da organização. Além da avaliação realizada pelo gestor, há outras formas de avaliação em função da otimização do programa, como a investigação in loco de ações e práticas do PPA, a realização de entrevistas às chefias sobre o aposentável participante do programa, os gestores de outras áreas, dos aposentáveis e dos que já se aposentaram. Uma das formas de confirmar a eficácia do PPA é comparar o bem-estar e satisfação na aposentadoria, entre os aposentados que participaram de PPA e outros que dele não participaram, analisando o efeito, inclusive, longitudinalmente.

A sistematização, expansão e avaliação do PPA precisam estar presentes na discussão entre profissionais, pesquisadores, formuladores de políticas e gestores sobre decisões e planejamentos de ações direcionadas à aposentadoria, bem como sobre o investimento e a administração adequados dos recursos públicos e privados para este fim. O PPA deve sobretudo estar em sintonia com a sustentabilidade da previdência, da qual o aposentado depende para realizar seus projetos de vida.

Programas que considerem tais aspectos e temáticas, possivelmente terão mais chances de serem bem-sucedidos e de promover satisfação e ajuste à aposentadoria em seus participantes. Assim, diversos estudos são necessários dentro da perspectiva intergeracional, multidisciplinar e interinstitucional. Tais estudos podem tornar visíveis iniciativas de sucesso, que devem ser compartilhadas, estimuladas e potencializadas.

\section{Referências}

Antunes, M. H., Soares, D. H. P., \& Silva, N. (2015). Orientação para aposentadoria nas organizações: Histórico, gestão de pessoas e indicadores para uma possível associação com a gestão do conhecimento. Perspectivas em Gestão \& Conhecimento, 5(1), 43-63. Recuperado em 15 junho, 2018, de: http://www.periodicos.ufpb.br/ojs/index.php/pgc/article/view/19114.

Brasil (1994). Lei n. ${ }^{\circ} 8.842$, de 4 de janeiro de 1994. Dispõe sobre a Política Nacional do Idoso, cria o Conselho Nacional do Idoso e dá outras providências. Brasília, DF. Recuperado em 26 dezembro, 2017, de http://www.planalto.gov.br/ccivil_03/leis/L8842.htm.

Brasil (2003). Lei n. ${ }^{o} 10.741$, de 1 de outubro de 2003. (2003). Dispõe sobre o Estatuto do Idoso e dá outras providências. Brasília, DF. Recuperado em 26 dezembro, 2017, de http://www.planalto.gov.br/ccivil_03/leis/2003/L10.741.htm. 
Bressan, M. A. L. C., Mafra, S. C. T., França, L. H. F. P., Melo, M. S. S., \& Loretto, M. D. S. (2013). Bem-estar na aposentadoria: O que isto significa para os servidores públicos federais? Revista Brasileira de Geriatria e Gerontologia, 6(2), 259-272. Recuperado em 20 janeiro, 2018, de: doi: 10.1590/S1809-98232013000200006.

Damman, M. B. (2016). Work and employment participation of older workers: A further discussion. Work, Aging and Retirement, 2(4), 384-389. Recuperado em 18 dezembro, 2017, de: doi: 10.1093/workar/waw022.

Dingemons, E., Henkens, K., \& Solinge, H. (2015). Access to bridge imployment: who finds and who does not find work after retirement? The Gerontologist, 56(4), 630-640. Recuperado em 18 dezembro, 2017, de: http://doi.org/10.1093/geront/gnu182.

Earl, J. K., Gerrans, P., \& Halim, V. A. (2015). Active and adjusted: Investigating the contribution of leisure, health and psychosocial factors to retirement adjustment. Leisure Sciences, 37, 354-372. Recuperado em 15 dezembro. 2017, de: doi: 10.1080/01490400.2015.1021881.

Figueira, D. A. M., Haddad, M. C. L., \& Gvozd, R. (2016). Percepções de trabalhadores préaposentados de uma instituição universitária pública acerca da aposentadoria. Revista da Rede de Enfermagem do Nordeste, 17(4). Recuperado em 25 setembro, 2018, de: doi: 10.15253/2175-6783.2016000400013.

Figueira, D. A. M., Haddad, M. C. L., Gvozd, R., \& Pissinati, P. S. C. (2017). Tomada de decisão de aposentadoria influenciada pelas relações familiares e de trabalho. Revista Brasileira de Geriatria e Gerontologia, 20(2), 206-213. Recuperado em 20 outubro, 2018, de: 10.1590/1981-22562017020.160127.

França, L. H. F. P. (1992). Terceira Idade: O trabalho social com idosos no SESC e os programas de preparo para aposentadoria nas empresas. Revista Administração Pública, 26(3), 174-181. Recuperado em 11 fevereiro, 2018, de: doi: http://bibliotecadigital.fgv.br/ojs/index.php/rap/article/view/8788/7527.

França, L. H. F. P. (2002). Repensando a aposentadoria com qualidade: um manual para facilitadores de programas de educação para aposentadoria em comunidades. Rio de Janeiro, RJ: CRDE UnATI UERJ. Recuperado em 12 fevereiro, 2018, de: http://www.crdeunati.uerj.br/publicacoes/pdf/repensando.pdf.

França, L. H. F. P., (2012). Envelhecimento dos trabalhadores nas organizações: estamos preparados? In: França, L. H. F. P., \& Stepansky, D. V. (Orgs.). Propostas multidisciplinares para o bem-estar na aposentadoria, 25-52. Rio de Janeiro, RJ: Faperj e Editora Quartet.

França, L. H. F. P. (2016). Programas de preparação para a aposentadoria: Diagnóstico e estratégias para implantação. In: Mendonça, H., Ferreira, M. C., \& Neiva, E. R. (Orgs.). Análise e diagnóstico organizacional, 319-347. São Paulo, SP: Vetor.

França, L. H. F. P., Menezes, G. S., \& Siqueira-Brito, A. R. (2012). Planejamento para Aposentadoria: a Visão dos Garis. Revista Brasileira Geriatria e Gerontologia, 15(4), 733 745. Recuperado em 12 fevereiro, 2018, de: doi: 10.1590/S1809-98232012000400012.

França, L. H. F. P, Nalin, C. P., Siqueira-Brito, A. R., Amorim, S. M., Talmo Rangel, T., \& Ekman, N. C. (2014). A percepção dos gestores brasileiros sobre os programas de preparação para aposentadoria. Estudos interdisciplinares sobre o envelhecimento, 9(3), 879-898. Recuperado em 12 fevereiro, 2018, de: doi: 10.1590/S0102-79722014000100001. 
França, L. H. F. P., \& Soares, D. H. P. (2009). Preparação para a aposentadoria como parte da educação ao longo da vida. Psicologia Ciência e Profissão, 29(4), 738-751. Recuperado em 11 fevereiro, 2018, de: doi: 10.1590/S1414-98932009000400007.

França, L. H. F. P., \& Vaughan, G. (2008). Ganhos e perdas na aposentadoria: percepção dos executivos brasileiros e neozelandeses. Psicologia em Estudo, 13(2), 207-216. Recuperado em 12 fevereiro, 2018, de: doi: 10.1590/S1413-73722008000200002.

Guerson, L. R. S. C., França, L. H. F. P., \& Amorim, S. M. (2018). Satisfação com a Vida em Aposentados que Continuam Trabalhando. Paidéia, 28(12), 1-8. Recuperado em 12 outubro, 2018, de: doi:10.1590/1982-4327e2812.

Instituto Brasileiro de Geografia e Estatística (2013). Projeção da População do Brasil. Recuperado em 20 dezembro, 2017, de: https://brasilemsintese.ibge.gov.br/populacao/taxasde-fecundidade-total.html.

Instituto Brasileiro de Geografia e Estatística. (2017). Tábua completa de mortalidade para o Brasil - 2016. Breve análise da evolução da mortalidade no Brasil. Brasília, DF. Recuperado em 26 dezembro, 2017, de: ftp://ftp.ibge.gov.br/Tabuas_Completas_de_Mortalidade/Tabuas_Completas_ de_Mortalidade_2016/tabua_de_mortalidade_2016_analise.pdf.

Instituto Brasileiro de Geografia e Estatística. (2018). Sinopse do Censo Demográfico de 2010. Rio de Janeiro. Recuperado em 28 março, 2018, de: https://censo2010.ibge.gov.br/sinopse/index.php.

Kerry, M. J. (2018). Psychological antecedents of Retirement Planning: a systematic review. Frontiers in Psychology, 9:1870, 1-17. Recuperado em 02 novembro, 2018, de: doi: 10.3389/fpsyg.2018.01870.

Leandro-França, C., Murta, S. G., \& Villa, M. B. (2014). Efeitos de uma intervenção breve no planejamento para a aposentadoria. Revista Psicologia: Organizações e Trabalho, 14(3), 257270. Recuperado em 15 abril, 2018, de: http://pepsic.bvsalud.org/scielo.php?script=sci_arttext\&pid=S1984-66572014000300002.

Leandro-França, C., Murta, S. G., Hershey, D., \& Martins, L. (2016). Evaluation of retirement planning programs: A qualitative analysis of methodologies and efficacy. Educational Gerontology, 42, 1-39. Recuperado em 15 abril, 2018, de: doi: 10.1080/03601277.2016.1156380.

Leandro-França, C., Seidl, J., \& Giardini Murta, S. (2015). Intervenção breve como estratégia de planejamento para aposentadoria: transformando intenções em ações. Psicologia em Estudo, 20(4). Recuperado em 15 abril, 2018, de: doi: 10.4025/psicolestud.v20i4.27413.

Leung, C. S. Y., \& Earl, J. K. (2012). Retirement resources inventory: Construction, factor structure and psychometric properties. Journal of Vocational Behavior, 81(2), 171-182. Recuperado em 28 abril, 2018, de: doi: 10.1016/j.jvb.2012.06.005.

Menezes, G. S., \& França, L. H. F. P. (2012). Preditores da decisão da aposentadoria por servidores públicos federais. Revista Psicologia Organizações e Trabalho, 12(3), 315-328. Recuperado em 26 dezembro, 2017, de: http://pepsic.bvsalud.org/scielo.php?script=sci_arttext\&pid=S1984-66572012000300006. 
Murta, S. G., Abreu, S., Leandro-França, C., Pedralho, M., Seidl, J., Lira, N. P. M., Carvalhedo, R. K. M., Conceição, A. C., \& Gunther, I. A. (2014). Preparação para a aposentadoria: implantação e avaliação do programa viva mais! Psicologia: Reflexão e Crítica, 27(1), 01-09. Recuperado em 14 abril, 2018, de: doi: 10.1590/S010279722014000100001

Organização das Nações Unidas. (1982). Plano de Ação Internacional de Viena Sobre o Envelhecimento. Recuperado em 29 dezembro, 2017, de: http://www.un.org/en/development/devagenda/ageing.shtml

Peiró, J. M., Tordera, N., \& Potocnik, K. (2012). Retirement practices in different countries. The Oxford Handbook of Retirement, 510-540. Recuperado em 12 maio, 2018, de: doi: 10.1093/oxfordhb/9780199746521.013.0157.

Pissinati, P. S. C., Haddad, M. C. F. L., Dalmas, J. C., \& Birolim, M. M. (2016). Fatores sociodemográficos e ocupacionais associados aos ganhos e perdas percebidos por trabalhadores de uma universidade pública frente à proximidade da aposentadoria. Cadernos de Saúde Pública, 32(9). Recuperado em 15 outubro, 2018, de: doi: 10.1590/0102$311 \times 00141415$.

Prochaska, J.O. \& Di Clemente, C.C. (1982). Terapia transteórica: Rumo a um modelo de mudança mais integrador. Psychotherapy: Theory, Research \& Practice, 19, 276288. Recuperado em 15 novembro, 2018, de: doi: 10.1037 / h0088437.

Sartori, I., Fraga, L. S., Vieira, K. M., \& Coronel, D. A. (2016). Os servidores públicos estão aderindo a FUNPRESP?: um estudo em uma instituição federal de ensino. Revista de Políticas Públicas, 20(2), 587-612. Recuperado em 15 outubro, 2018, de: 10.18764/21782865.v20n2p587-612.

Soares, D. H. P., Costa, A., Rosa, A. M., \& Oliveira, M. L. (2007). Aposenta-ação: programa de preparação para aposentadoria. Estudos Interdisciplinares sobre o Envelhecimento, 12, 143-161. Recuperado em 13 maio, 2018, de: doi: https://seer.ufrgs.br/RevEnvelhecer/article/view/4984/2853.

Wang, M., \& Shi, J. (2014). Psychological Research on Retirement. Annual Review of Psychology, 65(1), 210-228. Recuperado em 15 março, 2018, de: doi: 10.1146/annurevpsych-010213-115131.

Wang, M., \& Shultz, K. (2010). Employee retirement: A review and recommendations for future investigations. Journal of Management, 36(1), 172-206. Recuperado em 06 fevereiro, 2018, de: doi: 10.1177/0149206309347957.

Wang, M., Henkens, K., \& Solinge, H. (2011). Retirement adjustment: A review of theoretical and empirical advancements. American Psychologist, 66(3), 204-213. Recuperado em 06 fevereiro, 2018, de: 10.1037/a0022414.

Zanelli, J. C. \& Silva, N. (1996). Programa de preparação para aposentadoria. Florianópolis, SC: Insular.

Zanelli, J. C., Silva, N., \& Soares, D. H. (2010). Orientação para aposentadoria nas organizações de trabalho: Construção de projetos para o pós-carreira. Porto Alegre, RS: Artmed.

Zanelli, J. C. (2012). Processos psicossociais, bem-estar e estresse na aposentadoria. Revista Psicologia: Organizações e Trabalho, 12(3), 329-340. Recuperado em 15 agosto, 2018, de: doi: http://pepsic.bvsalud.org/scielo.php?script=sci_arttext\&pid=S1984-66572012000300007. 
Recebido em 30/01/2019

Aceito em 30/03/2019

Lucia Helena de Freitas Pinho França - Psicóloga. PhD em Psicologia, The University of Auckland. Professor titular do Programa de Pós-Graduação em Psicologia (PPGP) da Universidade Salgado de Oliveira, UNIVERSO, Niterói, RJ.

Orcid: https://orcid.org/000-0001-6716-7217

E-mail: lucia.franca@gmail.com

Soniárlei Vieira Leite - Advogado. Coordenador e Professor Adjunto da Universidade Veiga de Almeida, Professor da Universidade Salgado de Oliveira e da Fundação Getúlio Vargas. Doutor em Ciências Jurídicas e Sociais. Doutor em Psicologia, Universidade Salgado de Oliveira.

Orcid: https://orcid.org/000-0002-5587-3787

E-mail: soniarlei.vieira@gmail.com

Fabrícia Prado Simões - Oficial de Justiça e Avaliador Federal. Mestranda em Psicologia, PPGP, Universidade Salgado de Oliveira.

Orcid: https://orcid.org/0000-0002-9603-2853

E-mail: faprsimoes@gmail.com

Thaysa Garcia - Psicóloga. Mestranda em Psicologia, PPGP, Universidade Salgado de Oliveira.

Orcid: https://orcid.org/0000-0003-1875-9296

E-mail: thaysa.tyg@gmail.com

Patrick Ataliba - Pedagogo. Doutorando em Psicologia, PPGP, Universidade Salgado de Oliveira.

Orcid: https://orcid.org/0000-0003-1724-9745

E-mail: patrickataliba@gmail.com 
Obs.: Este projeto obteve apoio da Faperj, para a realização da pesquisa (2013-2016).

\section{ENDEREÇO PARA CORRESPONDÊNCIA}

Universidade Salgado de Oliveira, Universo

Rua Marechal Deodoro, 217 - Centro - Niterói/RJ. CEP 24020-420

E-mail: lucia.franca@gmail.com 